\title{
The Clinical Analysis of Bile Duct Injury during Laparoscopic Cholecystectomy
}

\author{
Zhenfeng Gao1, Peizhi Li², Fangzhang Chen1, Dingyong Tan ${ }^{*}$ \\ ${ }^{1}$ Department of Minimally Invasive Surgery, The Wanzhou District People's Hospital, Chongqing, China \\ ${ }^{2}$ Department of Hepatobiliary Surgery, The Second Affiliated Hospital of Chongqing Medical University, \\ Chongqing, China \\ Email: ${ }^{*} 594104007 @ q q . c o m$
}

Received 7 October 2015; accepted 10 November 2015; published 13 November 2015

Copyright (C) 2015 by authors and Scientific Research Publishing Inc.

This work is licensed under the Creative Commons Attribution International License (CC BY). http://creativecommons.org/licenses/by/4.0/

(c) (7) Open Access

\section{Abstract}

The study was to improve surgical safety and reduce the incidence of bile duct injury (BDI) during laparoscopic cholecystectomy. The clinical information of 31 cases with bile duct injury during Laparoscopic Cholecystectomy (LC) was analyzed retrospectively. Thirty patients with bile duct injury were divided into 5 types according to Bismuth typing, including: type I 9 cases, type II 12 cases, type III 4 cases, type IV 3 cases, type V 3 cases. After median follow-up of 48 months, 30 (97\%) patients are alive and $29(94 \%)$ remain in good general condition with normal liver function. One patient died from acute obstructive suppurative cholangitis (AOSC). One patient appeared to have pain under the xiphoid that was resolved after 3 months. Recurrent strictures following repair have developed in two $(6 \%)$ patients with high injuries combined with right hepatic arterial injury. Appropriate surgical indications, handling Calot triangle carefully and correctly, and conversion to open surgery at the right moment are the keys of prevention and treatment of bile duct injury during $L C$.

\section{Keywords}

Laparoscopy Cholecystectomy, Bile Duct Injury, Treatment

\section{Introduction}

Laparoscopic cholecystectomy (LC) was first introduced in 1991 in China. Because of its minimal invasion, less pain, faster recovery and other advantages, LC was accepted fast by the majority of doctors and patients as the gold standard for surgical treatment of benign gallbladder disease [1]. However, numerous reports have de-

\footnotetext{
*Corresponding author.
}

How to cite this paper: Gao, Z.F., Li, P.Z., Chen, F.Z. and Tan, D.Y. (2015) The Clinical Analysis of Bile Duct Injury during Laparoscopic Cholecystectomy. International Journal of Clinical Medicine, 6, 825-830. 
monstrated that the incidence of bile duct injury has risen from $0.1 \%$ to $0.2 \%$ in the era of open cholecystectomy to $0.4 \%$ to $0.7 \%$ in the era of laparoscopic cholecystectomy [2] [3]. As the complex conditions of bile duct injury, the difficulties of its management. Iatrogenic bile duct injury may lead to great suffering for the patients. So, the discussion of prevention, timely and correct treatment of bile duct injury in LC is particularly necessary.

\section{Patients and Methods}

From January 2000 to January 2010, thirty-one patients with bile duct injury were treated in Second Affiliated Hospital of Chongqing Medical University and the Wanzhou people's Hospital in China. These patients who were included in the study were diagnosed with clinical manifestation and imageological examination after LC. Among these patients 12 were males and 19 females (1:1.5), with a mean age of 41.2 years (range 18 to 83). Three patients were found to have bile duct injury during the operation. Twenty-five patients appeared abdominal pain, fever, jaundice or bile leakage postoperative 1 week to 1 month. And bile duct injury were found by imaging examination such as Ultrasound, Computed Tomography (CT) or Endoscopic Retrograde Cholangiopan-creatography (ERCP). Three patients appeared recurrent cholangitis or obstructive jaundice after 1 month of LC. They were diagnosed by ERCP or Percutaneous Transhepatic Cholangiography (PTC).

\section{Results}

\subsection{The Clinical Characteristics}

The clinical characteristics of the patients which included classification of bile duct injury [2] and the methods of examination were summarized in the Table 1. And some imaging findings are shown in Figure 1. In these 31 patients, 3 cases caused by anatomical variation, the other were because of the false recognition for Calot's triangle.

\subsection{Treatment for Bile Duct Injury}

The patients who were found bile duct injury during the operation were converted to open surgery. The breakdown of bile duct was less than $0.3 \mathrm{~cm}$ and was noticed by bile leakage. The injured duct was transverse sutured and there was no need for $\mathrm{T}$ tube drainage. Because the bile leaked into the peritoneum and caused inflammatory edema, the patients who were found bile duct injury 24 - $72 \mathrm{~h}$ after LC needed second operation such as proximal bile duct drainage and additional abdominal drainage until the inflammation subsided, while some were primary repaired or had a reconstruction of the biliary tract. These patients all underwent Roux-Y anastomosis. Three patients with bile duct stenosis caused by bile duct injury underwent resection of stenosis (Figure 2(C)), duct anastomosis or bile duct jejunum Roux-Y anastomosis (Figure 2(A), Figure 2(B), Figure 2(D)).

Table 1. The clinical characteristics of patients.

\begin{tabular}{|c|c|c|c|c|}
\hline $\begin{array}{l}\text { Bismuth } \\
\text { classification }\end{array}$ & & Clinical manifestation & Methods & cases \\
\hline Type I & $\begin{array}{l}\text { Low CBD stricture, with a length of the common } \\
\text { hepatic duct stump of }>2 \mathrm{~cm} \text {. }\end{array}$ & $\begin{array}{l}\text { Abdominal pain, } \\
\text { fever, jaundice }\end{array}$ & Ultrasound or CT & 9 \\
\hline Type II & Proximal CBD stricture-hepatic duct stump $<2 \mathrm{~cm}$ & $\begin{array}{l}\text { Abdominal pain, } \\
\text { fever, jaundice }\end{array}$ & Ultrasound or CT & 12 \\
\hline Type III & $\begin{array}{l}\text { Hilar stricture, no residual CBD, but the hepatic } \\
\text { ductal confluence is preserved. }\end{array}$ & $\begin{array}{l}\text { Bileleakageor bile } \\
\text { peritonitis }\end{array}$ & ERCP or PTC & 4 \\
\hline Type IV & $\begin{array}{l}\text { Hilar stricture, with involvement of confluence } \\
\text { and loss of communication between right and left } \\
\text { hepatic duct. }\end{array}$ & $\begin{array}{l}\text { Bile leakage or bile } \\
\text { peritonitis }\end{array}$ & ERCP or PTC & 3 \\
\hline Type V & $\begin{array}{l}\text { Involvement of aberrant right sectoral hepatic duct } \\
\text { alone or with concomitant stricture of the CBD. }\end{array}$ & $\begin{array}{l}\text { Reccurent } \\
\text { cholangitisor bile } \\
\text { peritonitis }\end{array}$ & ERCP & 3 \\
\hline
\end{tabular}

CBD, common bile duct. 

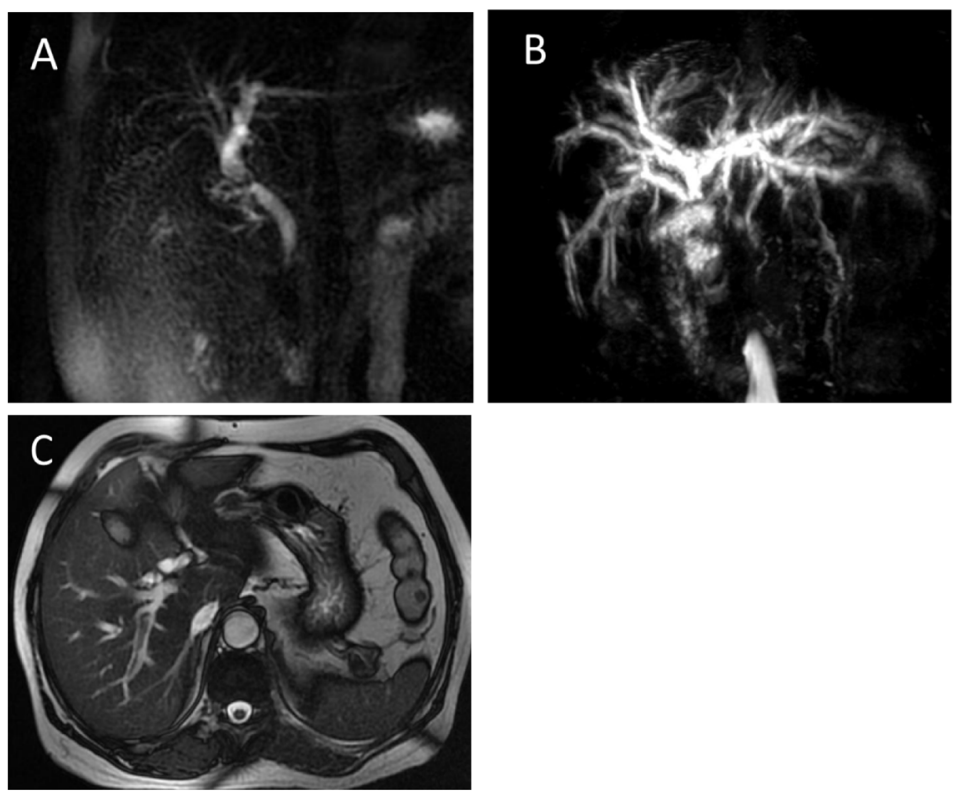

Figure 1. (A) (B) Magnetic resonance cholangiopancreatographic (MRCP) with three-dimensional reconstruction. Proximal common bile duct (CBD) stricture-hepatic duct stump $<2 \mathrm{~cm}$; (C) Magnetic resonance (MR) indicated dilated intrahepatic bile duct.
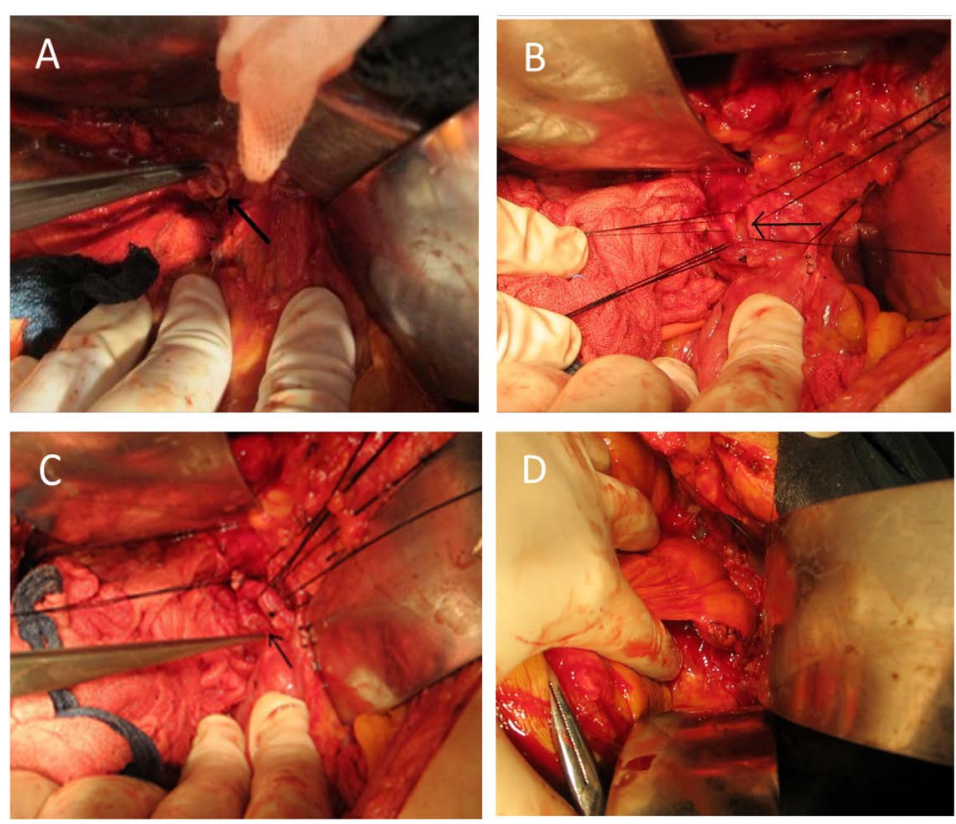

Figure 2. (A) Transected common bile duct (CBD) ( $\uparrow$ ); (B) Longitudinal incision common bile duct $(\uparrow)$; (C) Low CBD stricture, with a length of the common hepatic duct stump of $>2 \mathrm{~cm}(\uparrow)$; (D) Bile duct jejunum Roux-Y anastomosis.

\subsection{The Prognosis of Patients}

After treatment, one patient died due to obstructive suppurative cholangitis, the rest were discharged. After treatment, all 31 patients were followed up to 8 - 48 months, mean 18 months. One patient suffered from abdominal pain under the xiphoid which was resolved within 3 months without any treatment. Recurrent strictures 
following repair developed in two (6\%) patients with high injuries combined with right hepatic arterial injury. These two patients underwent bile duct jejunum Roux-Y anastomosis again.

\section{Discussion}

\subsection{The Main Reasons for Intraoperative Bile Duct Injury}

Bile duct injury is a major complication of LC. Anatomical anomalies, local pathology, and poor surgical techniques are the main factors responsible [4]. Anatomic factors include bile duct variation, variation of the cystic duct, abnormal blood vessels, and hepatic portal rotation. Bile duct variations include the following types: right hepatic duct goes through the gallbladder triangle and enters into the cystic duct; Right hepatic duct directly peached into the gallbladder ampulla; Larger accessory right hepatic duct enters the gallbladder ampulla or cystic duct; No right hepatic duct trunk, the right anterior and right posterior lobe hepatic ducts join the common hepatic duct separately, this form is called the split-type. Above all, accessory hepatic duct variation was one of the important anatomical biliary damage factor [5]. According to this variation, we must dissect and free the space behind the gallbladder ampulla. We also have to confirm that there are no abnormal tubes before disarticulating the cystic duct and the cystic artery.

The variations of cystic duct include: short cystic duct, atrophic cholecystitis and abnormal position of the gallbladder. The length of a normal cystic duct is about $10 \mathrm{~mm}$. Cystic duct which is less than $10 \mathrm{~mm}$ but more than $5 \mathrm{~mm}$ is consider as short-type cystic duct. Vascular variations mainly refer to the variations of the cystic artery and right hepatic artery. Hepatic portal rotation is a rare phenomenon and may happen in the following conditions: Varieties of pathologic causes such as inflammation or cirrhosis may lead to hepatic lobe atrophy and compensatory hypertrophy of adjacent lobe of the liver, which make the first hepatic portal and hepatic segment or lobe split, rotate and shift in the axis of the inferior vena cava [5]. In the study, one patient were found short cystic duct. Two patients were found atrophic cholecystitis the variations of cystic duct.

Lack of professional skills of the surgeon is another important factor [6]. In the study, the other 28 cases were caused by this factor. This situation contained the performer lacking of proficiency in laparoscopic technique, inadequate understanding of the endoscopic anatomy, blind hemostasis or large surface cautery when accidental bleeding occurs, and so on.

\subsection{Management of Bile Duct Injury}

Only $25 \%-32.4 \%$ of injuries are recognized during the operation, which is considered as the best time to perform repair [7]. Immediate restoration for bile ducts or biliary-enteric drainage is crucial to the success of the surgery. The most common injury types are the mechanical injury or burns of the bile ducts and accessory hepatic duct. The key to treatment is early detection and correction. Mostly, a transection lesion of bile duct is due to shear injury. The ends tissue injury was lighter than the burns. End to end anastomosis of the bile duct should be done to restore the anatomical integrity of the biliary tract and retain the function of the sphincter of Oddi. This manner have good blood supply, no anastomotic tension and will not cause any narrowing. Drainage near the anastomosis would prevent secondary infection. [8] [9].

Early management for injuries is very important [8] [10]. The management of BDIs can be divided into nonoperative and operative repair as well as into early ( $<1$ week), intermediate ( 1 to 6 weeks), and delayed ( $>6$ weeks) repair. The method and timing of the repair depends on several factors. The extent of injury, the expertise of the surgeon and his team, the amount of acute inflammation in the area, and the hemodynamic stability of the patient are the most important factors in achieving successful repair. It is necessary to have careful long-term postoperative monitoring of liver function and good interdisciplinary cooperation, especially with the suggestion of radiologist [11] [12].

There are several methods of the early treatment which include Conservative treatment, a simple repair, end to end bile duct anastomosis, Roux-en-Y biliary-enteric anastomosis, pedicle flap repair, peritoneal drainage and ERCP and nasal bile duct drainage [13]. The indications for conservative treatment include bile leakage is less than $300 \mathrm{ml}$, with no peritonitis. Ultrasonography should be done to rule out collections under the liver. Maintaining unobstructed drainage and preventing drainage tube slippage is crucial. After several weeks bile leakage would resolve [14] [15].

End-to-end anastomosis of bile ducts has the advantage of maintaining the physiological function of the bi- 
liary tract. It is suitable for bile duct transaction which was found during the surgery and the defect length is less than $1.5 \mathrm{~cm}$. The contraindication is defect greater than $1.5 \mathrm{~cm}$, severe local inflammation, and poor general condition. If the defect is larger than $1.5 \mathrm{~cm}$, the bile duct defect should be underwent Roux-en-Y anastomosed. [16] [17]. The choledochoenterostomy will not subject to restrictions due to the length of bile duct defect, and the indications are broader. The contraindications are severe peritonitis and when the diameter of the injured bile duct is less than $3 \mathrm{~mm}$ [18]. In the study, the three patients who found injure underwent end-to-end anastomosis of bile ducts. The other patients underwent bile duct jejunum Roux-Y anastomosis again. And the prognosis were well.

\subsection{Bile Duct Injury Prevention during LC}

Although the incidence of bile duct injury during laparoscopic cholecystectomy is greater than during open cholecystectomy, it can be minimized using specific operative strategies and principles [7] [19]. The strategies include selection of the proper patients for LC based on the experience of the surgeon, careful dissection for Calot's triangle, selective using laparoscopic ultrasonography, and conversion to open cholecystectomy when needed. The following situations were suggested conversion to open surgery: 1 ) severe gallbladder contraction, edema, or suspected cancer; 2) Intraoperative finding of anatomical variations of the cystic duct; 3) Uncontrolled hemorrhage during the operation; 4) If there is bile leakage after the cystic duct was clipped; 5) Other unexpected circumstances such as failure to establish pneumoperitoneum, multiple adhesions due to previous upper abdominal surgery and inflammation, hypercapnia.

During LC, the relative position of the cystic duct, the cystic artery and the common bile duct should be clearly identified in order to avoid bile duct injury [1] [20]. The "critical view of safety" (CVS) technique recommends clearing the triangle of Calot of fat and fibrous tissue and taking the gallbladder off the lowest part of its attachment to the gallbladder bed. CVS clarifies the relations of the anatomic structures that should be divided, and therefore, it should be ideally and routinely applied in all LCs because of its highly protective role against bile duct injuries. Laparoscopic subtotal cholecystectomy is a safe and feasible alternative to conversion to open surgery during difficult laparoscopic cholecystectomy for patients with complicated cholecystitis [21].

\section{Conclusion}

Appropriate surgical indications, handling Calot triangle carefully and correctly, and conversion to open surgery at the right moment are the keys of prevention and treatment of bile duct injury during LC.

\section{References}

[1] Ou, Z.B., Li, S.W., Liu, C.A., Tu, B., Wu, C.X., Ding, X., et al. (2009) Prevention of Common Bile Duct Injury during Laparoscopic Cholecystectomy. Hepatobiliary \& Pancreatic Diseases International: HBPD INT, 8, 414-417.

[2] Lau, K.N., Sindram, D., Agee, N., Martinie, J.B. and Iannitti, D.A. (2010) Bile Duct Injury after Single Incision Laparoscopic Cholecystectomy. JSLS: Journal of the Society of Laparoendoscopic Surgeons/Society of Laparoendoscopic Surgeons, 14, 587-591. http://dx.doi.org/10.4293/108680810X12924466008646

[3] Joseph, M., Phillips, M.R., Farrell, T.M. and Rupp, C.C. (2012) Single Incision Laparoscopic Cholecystectomy Is Associated with a Higher Bile Duct Injury Rate: A Review and a Word of Caution. Annals of Surgery, 256, 1-6. http://dx.doi.org/10.1097/SLA.0b013e3182583fde

[4] Al-Kubati, W.R. (2010) Bile Duct Injuries Following Laparoscopic Cholecystectomy: A Clinical Study. Saudi Journal of Gastroenterology: Official Journal of the Saudi Gastroenterology Association, 16, 100-104. http://dx.doi.org/10.4103/1319-3767.61236

[5] Buddingh, K.T., Nieuwenhuijs, V.B., van Buuren, L., Hulscher, J.B., de Jong, J.S. and van Dam, G.M. (2011) Intraoperative Assessment of Biliary Anatomy for Prevention of Bile Duct Injury: A Review of Current and Future Patient Safety Interventions. Surgical Endoscopy, 25, 2449-2461. http://dx.doi.org/10.1007/s00464-011-1639-8

[6] Strasberg, S.M. (2013) A Teaching Program for the "Culture of Safety in Cholecystectomy” and Avoidance of Bile Duct Injury. Journal of the American College of Surgeons, 217, 751. http://dx.doi.org/10.1016/j.jamcollsurg.2013.05.001

[7] Soper, N.J. (2011) Prevention of Biliary Leaks. Journal of Gastrointestinal Surgery: Official Journal of the Society for Surgery of the Alimentary Tract, 15, 1005-1006. http://dx.doi.org/10.1007/s11605-011-1512-z

[8] Huang, Q., Liu, C.H., Zhu, C.L., Xie, F. and Hu, S.Y. (2013) The Choice of Surgical Timing for Biliary Duct Recon- 
struction after Obstructive Bile Duct Injury: An Experimental Study. Hepato-Gastroenterology.

[9] Lau, W.Y., Lai, E.C. and Lau, S.H. (2010) Management of Bile Duct Injury after Laparoscopic Cholecystectomy: A Review. ANZ Journal of Surgery, 80, 75-81. http://dx.doi.org/10.1111/j.1445-2197.2009.05205.x

[10] Nordin, A., Gronroos, J.M. and Makisalo, H. (2011) Treatment of Biliary Complications after Laparoscopic Cholecystectomy. Scandinavian Journal of Surgery: SJS: Official Organ for the Finnish Surgical Society and the Scandinavian Surgical Society, 100, 42-48.

[11] Karvonen, J., Gronroos, J.M., Makitalo, L., Koivisto, M. and Salminen, P. (2013) Quality of Life after Iatrogenic Bile Duct Injury-A Case Control Study. Minimally Invasive Therapy \& Allied Technologies, 22, 177-180. http://dx.doi.org/10.3109/13645706.2012.752751

[12] Thompson, C.M., Saad, N.E., Quazi, R.R., Darcy, M.D., Picus, D.D. and Menias, C.O. (2013) Management of Iatrogenic Bile Duct Injuries: Role of the Interventional Radiologist. Radiographics, 33, 117-134.

[13] Xu, X.D., Zhang, Y.C., Gao, P., Bahrani-Mougeot, F., Zhang, L.Y., He, Z.Y., et al. (2011) Treatment of Major Laparoscopic Bile Duct Injury: A Long-Term Follow-Up Result. The American Surgeon, 77, 1584-1588.

[14] Lovecek, M., Havlik, R., Klein, J., Maly, T., Kocher, M., Cerna, M., et al. (2010) Iatrogenic Bile Ducts Injuries. Rozhledy v Chirurgii: Mesicnik Ceskoslovenske Chirurgicke Spolecnosti, 89, 183-187.

[15] Macedo, F.I., Casillas, V.J., Davis, J.S., Levi, J.U. and Sleeman, D. (2013) Biliary-Colonic Fistula Caused by Cholecystectomy Bile Duct Injury. Hepatobiliary \& Pancreatic Diseases International, 12, 443-445. http://dx.doi.org/10.1016/S1499-3872(13)60070-3

[16] Lubikowski, J., Post, M., Bialek, A., Kordowski, J., Milkiewicz, P. and Wojcicki, M. (2011) Surgical Management and Outcome of Bile Duct Injuries Following Cholecystectomy: A Single-Center Experience. Langenbeck's Archives of Surgery, 396, 699-707. http://dx.doi.org/10.1007/s00423-011-0745-3

[17] Harrison, V.L., Dolan, J.P., Pham, T.H., Diggs, B.S., Greenstein, A.J., Sheppard, B.C., et al. (2011) Bile Duct Injury after Laparoscopic Cholecystectomy in Hospitals with and without Surgical Residency Programs: Is There a Difference? Surgical Endoscopy, 25, 1969-1974. http://dx.doi.org/10.1007/s00464-010-1495-y

[18] Pesce, A., Portale, T.R., Minutolo, V., Scilletta, R., Li Destri, G. and Puleo, S. (2012) Bile Duct Injury during Laparoscopic Cholecystectomy without Intraoperative Cholangiography: A Retrospective Study on 1,100 Selected Patients. Digestive Surgery, 29, 310-314. http://dx.doi.org/10.1159/000341660

[19] Tantia, O., Sasmal, P.K., Patle, N. and Prasad, P. (2010) Bile Duct Injury during Laparoscopic Cholecystectomy: Mechanism and Prevention. Journal of the Indian Medical Association, 108, 667-668, 671.

[20] Fullum, T.M., Downing, S.R., Ortega, G., Chang, D.C., Oyetunji, T.A., Van Kirk, K., et al. (2013) Is Laparoscopy a Risk Factor for Bile Duct Injury during Cholecystectomy? JSLS: Journal of the Society of Laparoendoscopic Surgeons, 17, 365-370. http://dx.doi.org/10.4293/108680813X13654754535638

[21] Tian, Y., Wu, S.D., Su, Y., Kong, J., Yu, H. and Fan, Y. (2009) Laparoscopic Subtotal Cholecystectomy as an Alternative Procedure Designed to Prevent Bile Duct Injury: Experience of a Hospital in Northern China. Surgery Today, 39, 510-513. http://dx.doi.org/10.1007/s00595-008-3916-2 